\title{
Article \\ Vibration Actuator System with Small-Scale Size Capable of Visual Inspection of Large Complex Iron Structures
}

\author{
Hiroyuki Yaguchi *D and Yusuke Itoh \\ Faculty of Engineering, Tohoku Gakuin University, Tagajo 985-8537, Japan; mizusuhi81@gmail.com \\ * Correspondence: yaguchi@mail.tohoku-gakuin.ac.jp; Tel.: +81-223-687-104
}

Citation: Yaguchi, H.; Itoh, Y.

Vibration Actuator System with Small-Scale Size Capable of Visual Inspection of Large Complex Iron Structures. Appl. Sci. 2021, 11, 7467. https://doi.org/10.3390/app11167467

Academic Editor:

Giuseppe Lacidogna

Received: 17 July 2021

Accepted: 11 August 2021

Published: 14 August 2021

Publisher's Note: MDPI stays neutral with regard to jurisdictional claims in published maps and institutional affiliations.

Copyright: (c) 2021 by the authors. Licensee MDPI, Basel, Switzerland. This article is an open access article distributed under the terms and conditions of the Creative Commons Attribution (CC BY) license (https:// creativecommons.org/licenses/by/ $4.0 /)$.

\begin{abstract}
Deterioration of social infrastructure equipment has become a major problem in countries around the world. In the present study, a novel vibration actuator system capable of movement on an iron structure having complicated surfaces, such as steps, is proposed. A vibration actuator capable of reciprocating movement with a small-scale size was prototyped and tested. In consideration of mobility, the size of the vibration actuator is designed to be smaller than $50 \mathrm{~mm}$ and the total mass is lighter than $20 \mathrm{~g}$. The experimental result demonstrates that the maximum efficiency of the vibration actuator was $28.1 \%$, and the maximum pulling power was $1.8 \mathrm{~N}$. Furthermore, a vibration actuator system in which two vibration actuators and a wheel having a magnetic force connected by a flexible silicone rubber material was prototyped. This actuator system can move over a step of $48 \mathrm{~mm}$ in the horizontal plane and $25 \mathrm{~mm}$ in the vertical plane without control. Finally, a machine test was conducted on the frame surface moving, which is difficult even for robots. This actuator system can move at an average speed of $12.1 \mathrm{~mm} / \mathrm{s}$ within the frame.
\end{abstract}

Keywords: vibration actuator system; small-scale size; magnetic wheel; magnetic attractive force; complex iron structure; inspection

\section{Introduction}

Deterioration of social infrastructure equipment has become a major problem in countries around the world. In particular, the safety of bridges built 50 years ago has been of concern. Due to the increase in traffic volume, it has been reported that cracks occur due to the influence of moving vehicles. Old infrastructure was built without seismic standards, so there is a risk of collapse in the event of a natural disaster. Thus, accidents involving bridge collapse due to aging have occurred frequently. To prevent such accidents, efficient and regular inspection of old bridges is required. In particular, there is a high demand for inspection at the cable joint of a large cable-stayed bridge having a height of a main tower over $100 \mathrm{~m}$.

Numerous robots have been proposed for structural inspection. Adsorption methods for wall surface movement have used the following proposed techniques: suction cup [1-3], adhesive materials [4], claw gripper [5,6], van der Waals forces [7], and the negative pressure of a pump [8]. In a robot capable of movement on a non-magnetic material, the methods described above involve complicated mechanisms and require the adhered device to have a relatively large weight. In addition, the application of these robots was limited to materials with rough surfaces. Therefore, material-independent mobile robots are limited to laboratory-level applications because they require complex controls and many additional devices. Many flying type robots such as propeller type [9] and drone [10,11] are proposed. These robots require skill to operate and are easily affected by weather such as rain and wind.

On the other hand, many robots have been proposed targeting the movement of iron structures. Typical robots are magnetic caterpillar type [12] and wheel type [13,14]. Since these robots use many electromagnetic motors and reduction gears, their own weight 
increases. In addition, it requires a lot of control units, so it moves at low speed. Therefore, there is a demand for lightweight robots with excellent operability.

For the purpose of movement to iron structures, the authors invented a lightweight actuator with excellent operability and a very simple structure $[15,16]$. When this actuator is built into a robot, direct drive is possible without reduction gear mechanisms because this actuator has a high propulsion force. In addition, consideration about a reciprocating movement using two vibration components was accomplished [17]. However, these actuators [15-17] could not move even a slight step in a horizontal plane. The movement characteristics were significantly reduced due to vibration interference between the components. Furthermore, the author proposed a new actuator system that combines magnetic wheels and vibration components $[18,19]$. These wheel-type actuators can move on small steps on a horizontal surface, but cannot move on steps on a vertical surface. Further, the operation of movement on the step is complicated, and these cannot automatically move on the step. Thus, these actuators cannot move across horizontal surfaces that have large steps or vertical surfaces that have very small steps. Thus, despite the development of the above-mentioned robots and actuators, a technology for inspecting structures has not yet been established.

In the present study, a novel vibration actuator system capable of movement on a complex iron structure with large steps in the horizontal and vertical planes was proposed. The cooperative operation of the two vibration component, this actuator system can automatically move the large step in a vertical plane. First, the direction of movement for the actuator was examined, and a vibration actuator capable of reciprocating movement that has high efficiency was manufactured. In consideration of mobility, a scale size of the vibration actuator is designed to be smaller than $50 \mathrm{~mm}$ and a total mass is lighter than $20 \mathrm{~g}$. In addition, a vibration actuator system in which two vibration actuators and a wheel having a vibration force were connected by a flexible silicon rubber material was prototyped. By extending the operating principle proposed by the authors, a new type of the vibration actuator system that can be directly driven without using an electromagnetic motor or device has been proposed. The actuator system can move on vertical surfaces of complex iron structures with a step height of $25 \mathrm{~mm}$. Furthermore, as a result that the vibration actuator can be driven directly, the actuator system can be driven by simple devices such as signal generators, amplifiers and DC power supplies and does not require any special operation. Therefore, it is possible to move a step with a height of $20 \mathrm{~mm}$ on a vertical surface at a speed exceeding $20 \mathrm{~mm} / \mathrm{s}$. The total length of this actuator system is designed to be about $300 \mathrm{~mm}$ and the total mass is $68 \mathrm{~g}$. For this reason, the actuator system is superior in operability and mobility, and has the potential to be applied to on-site inspection. In addition, this actuator system can switch the movement characteristics by changing the attractive force of the actuator according to the inspection distance. When increasing the attractive force, the experimental results obtained by the actual mechanical test showed the possibility of visual inspection of the main tower of a large bridge over $100 \mathrm{~m}$.

Finally, a movement test was performed with a frame consisting of horizontal and vertical surfaces by varying the attractive force of the permanent magnets attached to the actuator system. By changing a part of silicone rubber frame in the actuator system, the possibility of inspection in the bridge girder was shown. It was shown that this actuator system could be applied to inspection of iron bridges and tanks by installing sensors such as cameras.

\section{Vibration Actuator Capable of Reciprocating Movement}

The reciprocating movement of the vibration actuator proposed by the authors was examined. The actuator moves in the tilted direction of the vibration component. To apply this principle, a newly designed slider mechanism that can move on a semi-cylinder was placed on the support of the vibration component. Four shape memory alloy springs were used to move the slider. Figure 1 shows the structure of the vibration actuator capable of reciprocating movement prototyped in the present study. This vibration actuator consists 
of a vibration component, a holder unit for reciprocating movement, a permanent magnet attached to the lower part of the holder unit, and natural rubber sheet. Figure 2 shows the dimensions of the vibration actuator. This actuator has a length of $40 \mathrm{~mm}$, a width of $38 \mathrm{~mm}$, a total height of $42 \mathrm{~mm}$, and is manufactured with dimensions smaller than $50 \mathrm{~mm}$.

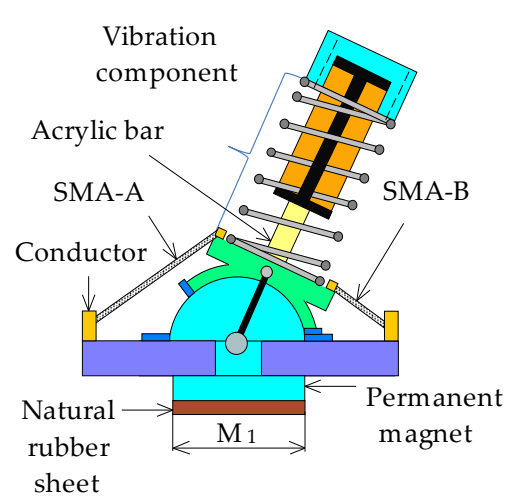

(a) Plan view

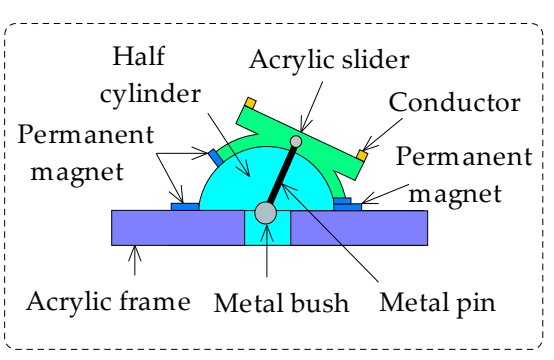

(c) Details of holder unit

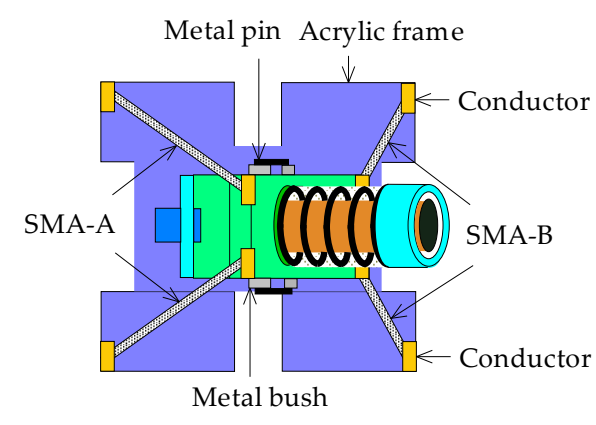

(b) Front view

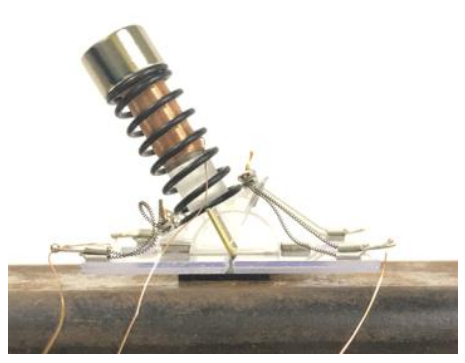

(d) Photograph

Figure 1. Structure of the vibration actuator capable of reciprocating movement. (a) Plan view of the actuator, (b) Front view of the actuator, (c) Details of holder unit of the actuator, (d) Photograph of the actuator.

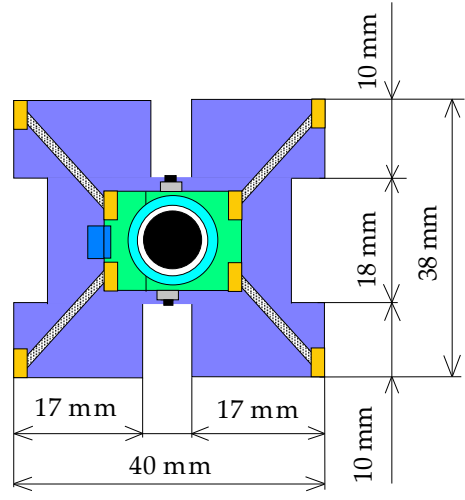

(a) Plan view

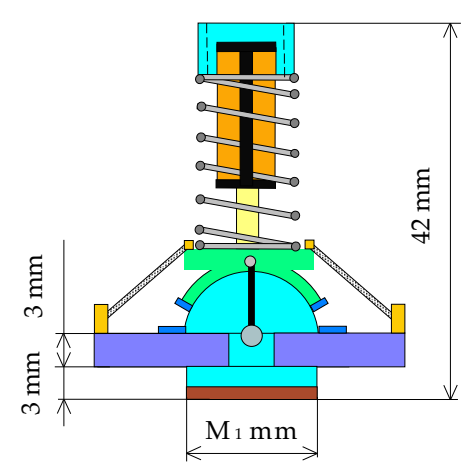

(b) Front view

Figure 2. Dimensions of vibration actuator. (a) Plan view of the actuator, (b) Front view of the actuator.

As shown in Figure 3, the vibration component is composed of a coil spring, a ringtype permanent magnet, and an electromagnet with a bobbin-type iron core proposed in a previous paper [15]. The coil spring is a compression coil spring with a free length of $25 \mathrm{~mm}$, an outer diameter of $12 \mathrm{~mm}$, and a spring constant of $\mathrm{k}=2689 \mathrm{~N} / \mathrm{m}$. The ring-type permanent magnet is an $\mathrm{NdFeB}$ magnet with an outer diameter of $12 \mathrm{~mm}$, an inner diameter of $9 \mathrm{~mm}$, and a thickness of $8 \mathrm{~mm}$ that is magnetized in the height direction. For the electromagnet, the experimental results of optimization of the bobbin-type iron core 
shape and the number of turns in a previous study [17] were applied. As shown in Figure 3, the diameter of the iron disk is $\mathrm{D}=8 \mathrm{~mm}$, the thickness is $\mathrm{h}=1 \mathrm{~mm}$, and the shaft diameter and length are $\mathrm{d}=3 \mathrm{~mm}$ and $\mathrm{H}=15.5 \mathrm{~mm}$, respectively. The electromagnet was produced by winding a copper wire with an outer diameter of $0.2 \mathrm{~mm}$ around a bobbin-type iron core, creating a coil with a total of 810 turns. Details of the electromagnet are shown in Table 1.

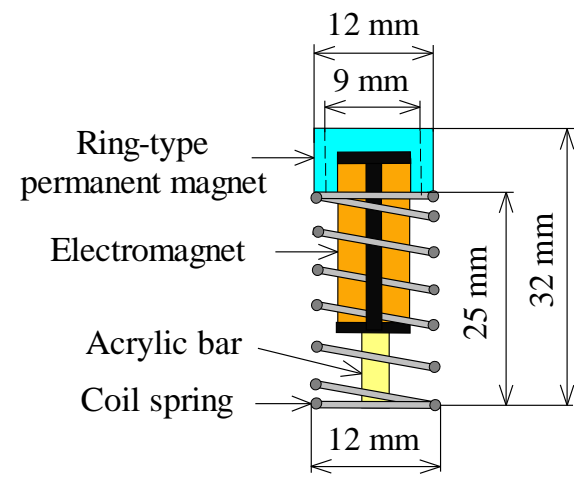

(a) Vibration component

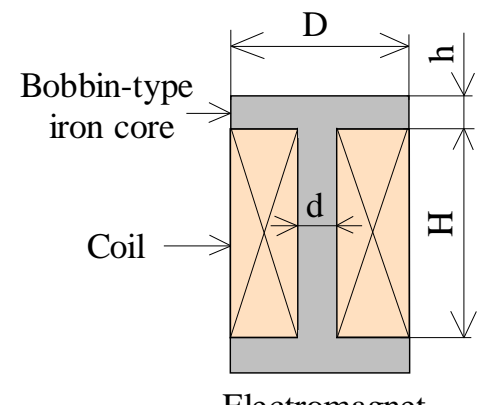

Electromagnet

(b) Electromagnet

Figure 3. Vibration components and electromagnets. (a) Vibration component of the actuator, (b) Electromagnet of the actuator.

Table 1. Specifications of the electromagnet.

\begin{tabular}{cccccc}
\hline Length $\mathbf{H}$ & Diameter $\mathbf{D}$ & Diameter $\mathbf{D}$ & Thickness $\mathbf{H}$ & Coil Turns & Resistance \\
\hline $17.5 \mathrm{~mm}$ & $8 \mathrm{~mm}$ & $3 \mathrm{~mm}$ & $1 \mathrm{~mm}$ & 810 & $7.2 \Omega$ \\
\hline
\end{tabular}

An NdFeB magnet having a length of $\mathrm{M}_{1}(\mathrm{~mm})$, a width of $\mathrm{M}_{2}(\mathrm{~mm})$, and a thickness of $\mathrm{M}_{3}$ (mm) was used as a permanent magnet below the holder unit. In this paper, two types I and II permanent magnets were used for the holder unit. In addition, a natural rubber sheet with a thickness of $1 \mathrm{~mm}$ was attached to the lower part of the permanent magnet to increase the frictional force. The vibration components are mounted at an angle of 60 degrees from the horizontal plane.

When this actuator is placed on a magnetic substance, such as an iron rail, the holder unit of the actuator receives an attractive force due to the permanent magnet, and the vibration component vibrates as a result of the electromagnetic force. The inertial force generated by the vibration component mounted at 60 degrees changes the frictional force between the magnetic material and the surface of the permanent magnet. Therefore, this actuator can move in the inclined direction of the vibration component [16].

Applying this principle of operation, the proposed vibration actuator with a holder unit capable of reciprocating movement was prototyped, as shown in Figure 4. As shown in Figure 1, the holder unit consists of an acrylic semi-cylinder, an acrylic base frame, four permanent magnets, four shape-memory alloy (SMA) coil springs, and an acrylic slider. In the holder unit, the acrylic semi-cylinder was attached to the base frame. The acrylic slider connected by two metal pins can rotate on the cylinder. Four SMA coil springs are attached to the frame and the slider via eight conductors. The SMA coil spring has a length of $30 \mathrm{~mm}$ and an outer diameter of $0.15 \mathrm{~mm}$. The SMA-A and SMA-B units were formed as a pair of these SMA coil springs. When a current of 0.2 A flows through each SMA unit and the shape memory alloy spring contracts, the slider rotates on an acrylic half-cone. By tilting the vibration component by this method, the direction of movement for the actuator can be switched as shown in Figure 4. After the vibration component is tilted, the acrylic semi-cylinder and the acrylic slider are held by the attractive force generated by the two permanent magnets even if the input current to the SMA coil spring is stopped. An NdFeB permanent magnet having a length of $4 \mathrm{~mm}$, a width of $5 \mathrm{~mm}$, and a thickness of $1 \mathrm{~mm}$ 
was attached to the base frame, and an NdFeB magnet having a length of $3 \mathrm{~mm}$, a width of $5 \mathrm{~mm}$, and a thickness of $1 \mathrm{~mm}$ was attached to the slider. The attractive force between the two magnets at the time of contact is $0.6 \mathrm{~N}$, and the holder unit is held by this attractive force. The proposed vibration actuator, which is capable of reciprocating movement, has a height of $42 \mathrm{~mm}$, a length of $40 \mathrm{~mm}$, a width of $38 \mathrm{~mm}$, and a total mass of $18 \mathrm{~g}$.

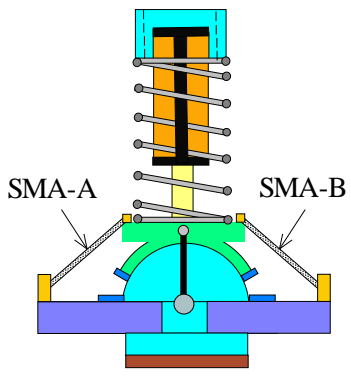

(a) Neutral

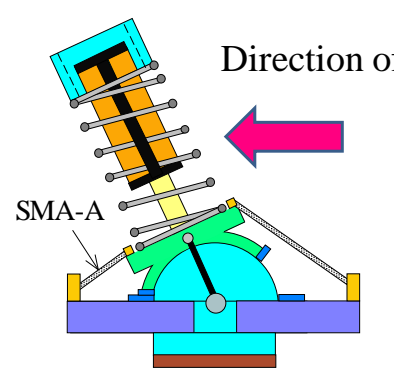

(b) Direction A

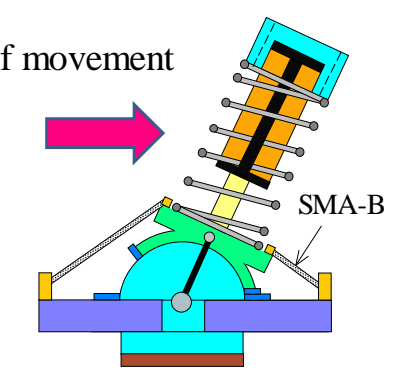

(c) Direction B

Figure 4. Movement direction of the vibration actuator.

\section{Locomotion Characteristics of the Proposed Vibration Actuator}

The movement characteristics for the vibration actuator designed in the previous chapter were measured. The speed and efficiency of the vibration actuator in the movement direction were examined in detail. Furthermore, changes in movement characteristics due to the attractive force of the holder unit in the vibration actuator were investigated. An experiment was conducted using the apparatus shown in Figure 5. In the experiment, an iron rail of $50 \mathrm{~mm}$ in width, $50 \mathrm{~mm}$ in thickness, and $1000 \mathrm{~mm}$ in length was used as the target magnetic structure. The vibration component was driven at the resonance frequency using a function signal generator and an amplifier. The resonance frequency was $128 \mathrm{~Hz}$. A DC power supply was used for current control of the SMA-A and SMA-B units. The load mass was attached to the actuator using a string. The vertical upward speed was measured by tilting the vibration component in the A and B directions as shown in Figure 5.
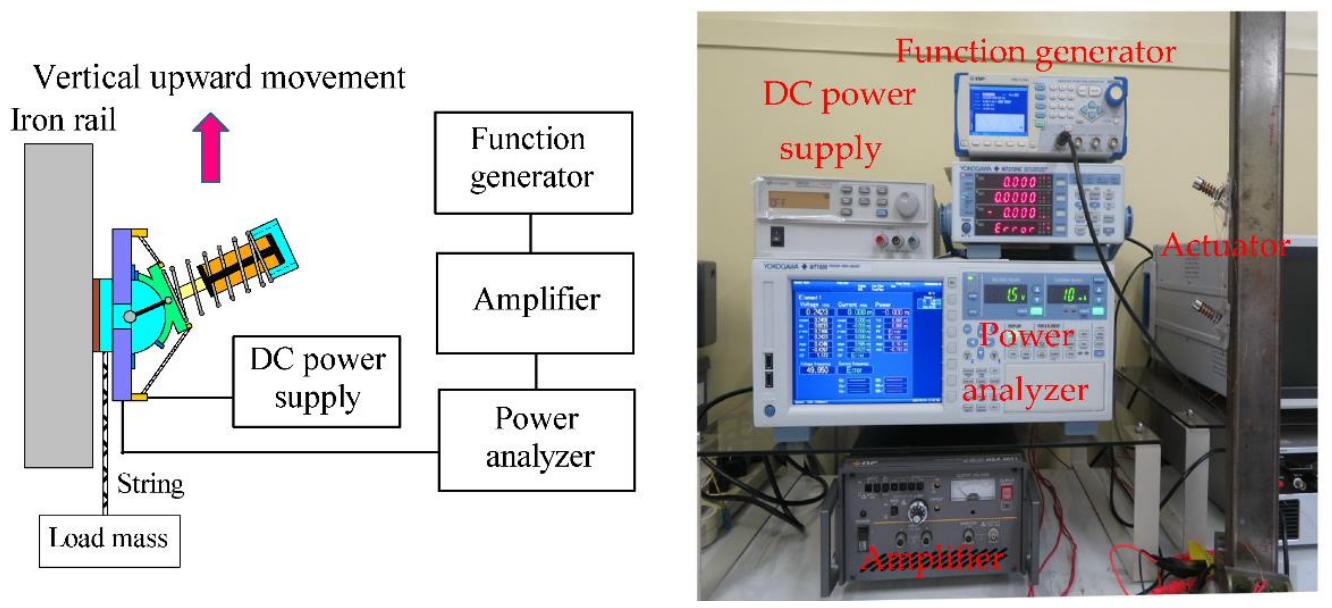

Figure 5. Experimental apparatus.

The measurement was performed for two cases in which the dimensions of the $\mathrm{NdFeB}$ permanent magnet attached to the lower part of the holder unit were as follows: (1) $\mathrm{M}_{1}=15 \mathrm{~mm}, \mathrm{M}_{2}=5 \mathrm{~mm}, \mathrm{M}_{3}=2 \mathrm{~mm}$, and (2) $\mathrm{M}_{1}=15 \mathrm{~mm}, \mathrm{M}_{2}=5 \mathrm{~mm}$, and $\mathrm{M}_{3}=3.5 \mathrm{~mm}$.

The average surface magnetic flux density for the permanent magnet of Type I measured using a tesla meter was $116 \mathrm{mT}$. The average surface magnetic flux density of Type II was $242 \mathrm{mT}$. Thus, the attractive forces $\mathrm{F}$ of the holder units placed on the iron rails Type I 
and II were $1.8 \mathrm{~N}$ and $3.7 \mathrm{~N}$, respectively. The coefficient of friction between the iron rail and the natural rubber as measured in the experiment was 0.67 .

The vibration component as shown in Figure 6a can replace the one-degree-of-freedommodel shown in Figure $6 \mathrm{~b}$ which has spring constant $k$, viscous damping coefficient $C$, and mass $\mathrm{m}$ of the ring-type permanent magnet. $\mathrm{F}$ is the attractive force by the permanent magnet below the holder unit when the actuator put on the iron rail, $\mu$ is coefficient of friction, $\alpha$ is tilt angle of the vibration component from a horizontal plane. For the case in which mass $m$ is subjected to exciting vibration Rsin $\omega$ t generated by the electromagnet. If the mass is treated as point mass $m$ and the displacements $x$ is measured as shown in Figure $6 \mathrm{~b}$, then the equations of translational motion can be written as follows:

$$
\mathrm{m} \frac{\mathrm{d}^{2} \mathrm{x}}{\mathrm{dt}^{2}}+\mathrm{C} \frac{\mathrm{dx}}{\mathrm{dt}}+\mathrm{kx}=\mathrm{R} \sin \omega \mathrm{t}
$$

where, $\omega$ is the angular frequency, $R$ is the force amplitude of the forced vibration, and $t$ is time. When the mass vibrates with amplitude $A$, the generating force $F_{s}$ acting on the support part of the vibration component is as follows:

$$
\left.\begin{array}{c}
\mathrm{kx}+\mathrm{C} \frac{\mathrm{dx}}{\mathrm{dt}}=-\mathrm{m} \frac{\mathrm{d}^{2} \mathrm{x}}{\mathrm{dt}^{2}}=\mathrm{F}_{\mathrm{s}} \sin (\omega \mathrm{t}-\theta-\phi) \\
\mathrm{F}_{\mathrm{s}}=\mathrm{A} \sqrt{\mathrm{k}^{2}+(\mathrm{C} \omega)^{2}}, \tan \theta=\frac{2 \zeta(\omega / \mathrm{p})}{\mathrm{p}^{2}-\omega^{2}}, \tan \phi=C \omega / \mathrm{k} \\
\mathrm{p}=\sqrt{\mathrm{k} / \mathrm{m}}, \zeta=\mathrm{C} / 2 \mathrm{mp}
\end{array}\right\}
$$

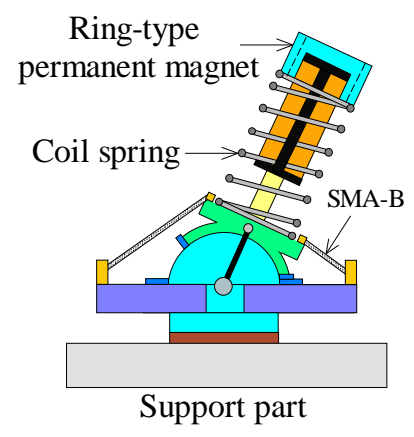

(a)

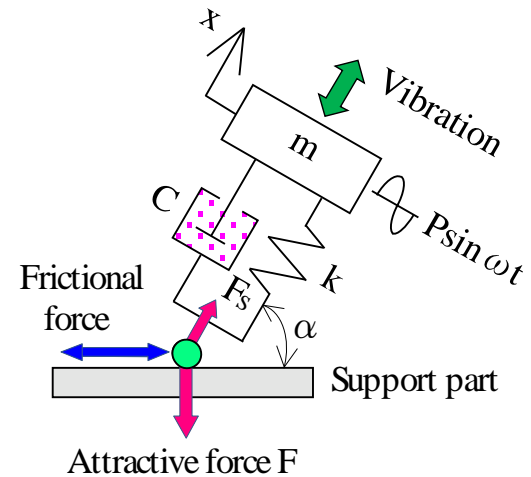

(b)

Figure 6. One-degree-of-freedom model. (a) Vibration component. (b) Equivalent model.

The frictional force between the natural rubber sheet and the iron rail alternates during one period of vibration. As a result, the vibration actuator is able to slide [16] only in the inclined direction of the vibration component as shown in Figure 1. In addition, it is necessary for attractive force $\mathrm{F}$ of the permanent magnet holding the vibration component to satisfy a next condition because the actuator moves.

$$
\mathrm{F}_{\mathrm{S}} \sin \alpha<\mathrm{F}<\mathrm{F}_{\mathrm{S}}(\cos \alpha+\mu \sin \alpha) / \mu
$$

As shown in the above inequality, when the vibration component generates the force exceeding the attractive force $\mathrm{F}$, the vibration actuator causes a jumping phenomenon.

The movement characteristics of this vibration actuator change depending on various parameters. When the viscous damping of the spring is small, even if the parameters of the vibration component are changed, the same movement characteristics can be obtained by adjusting the following five indicators.

1. Synchronize the resonance frequency of the vibration actuator.

2. The ratio of attractive force $F$ and generation force $F_{S}$ is set equally.

3. The elastic energy $0.5 \mathrm{kA}^{2}$ generated by the one-degree-of-freedom model is equal. 
4. The coefficient of friction for the natural rubber material is the same.

5. The total mass of the vibration actuator is set equally.

By satisfying the above indicators, it can be applied to actuators with various scales. Figure 7 shows the relationships between the load mass and the vertical upward speed and between the load mass and the efficiency when the input power to the electromagnet of the vibration component is $0.1 \mathrm{~W}$. The attractive force $\mathrm{F}$ of the holder unit was set to $1.8 \mathrm{~N}$. The solid line indicates the speed of the actuator, and the dashed line indicates the efficiency when pulling the weight of the actuator. In the figure symbols $\bullet$ and $\boldsymbol{\Delta}$ indicate the measurement results for Direction A, in which SMA-A coil spring was contracted, and symbols $\bigcirc$ and $\triangle$ indicate the measurement results for Direction B, in which SMA-B coil spring was contracted. Efficiency @ is expressed as follows:

$$
\eta[\%]=\left(M_{a}+M_{m}\right) v_{u p} g \times 100 / P_{I}
$$

where $M_{a}$ is the total mass of the actuator, $M_{m}$ is the load mass, $v_{u p}$ is the vertical upward speed, $\mathrm{g}$ is the acceleration due to gravity, and $\mathrm{P}_{\mathrm{I}}$ is the input power.

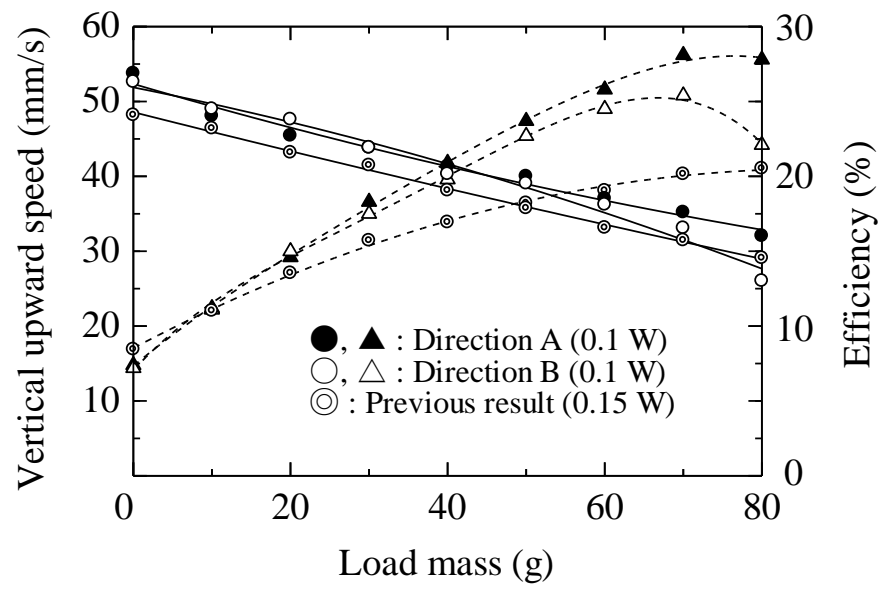

Figure 7. Relationships between load mass and speed and between load mass and efficiency $(\mathrm{F}=1.8 \mathrm{~N})$.

The maximum efficiencies of the actuator for the case in which the weight of the actuator is being pulled is $28.1 \%$ and $25.4 \%$ in Directions A and B, respectively. The () symbol in this figure indicates the results reported in a previous paper [17] when the input power to the vibration component was $0.15 \mathrm{~W}$ and the attractive force of the actuator was set to $2.55 \mathrm{~N}$. Compared to the previous study [17] using two vibration components, the maximum efficiency increased from $20.5 \%$ to $28.1 \%$ because there is no vibration interference, and the total mass of the actuator was reduced from $28 \mathrm{~g}$ to $18 \mathrm{~g}$. In the category of small-scale devices, considering this vibration actuator as a linear actuator, the results of the actual machine test show quite high efficiency and movement properties.

Figure 8 shows the relationships between the load mass and the vertical upward speed and between the load mass and the efficiency when the input power to the vibration component was $0.3 \mathrm{~W}$. The attractive force $\mathrm{F}$ of the holder unit was set to $3.7 \mathrm{~N}$. In this case, this actuator can move vertically at a speed of $17 \mathrm{~mm} / \mathrm{s}$ with a load mass of $150 \mathrm{~g}$. 


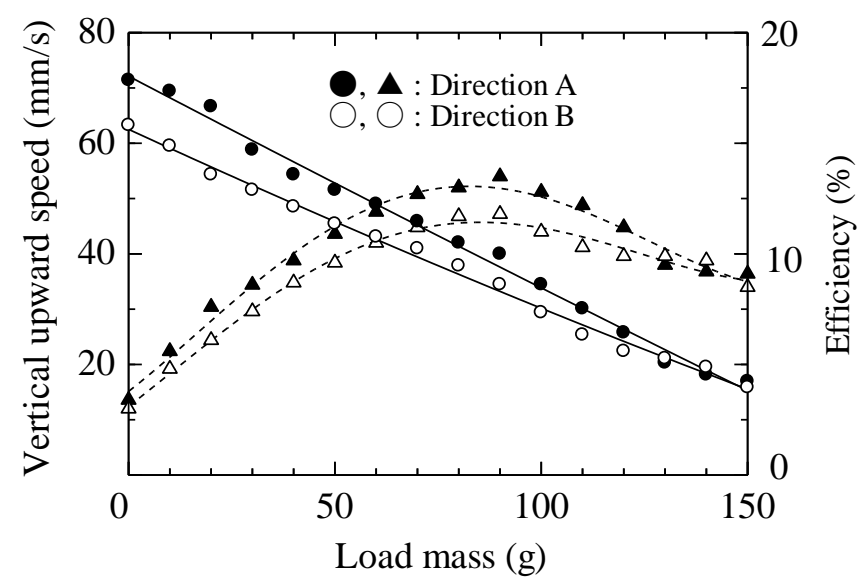

Figure 8. Relationships between load mass and speed and between load mass and efficiency $(\mathrm{F}=3.7 \mathrm{~N})$.

In the above measurement results, an error was found in the speed depending on the direction of the movement. This is because the components of the actuator are manufactured by a 3D processing machine, but are affected by hand-made assembly errors.

On the other hand, the attractive force F of the actuator is set to $3.7 \mathrm{~N}$, Figure 9 shows the relationship between the load mass and the vertical upward speed of the actuator when the input power to the electromagnet is changed to $0.3 \mathrm{~W}, 0.4 \mathrm{~W}$, and $0.5 \mathrm{~W}$. When the input power is $0.5 \mathrm{~W}$, the maximum tractive force is about $1.8 \mathrm{~N}$. From this figure, this actuator produces a tractive force of approximately 10 times its own weight.

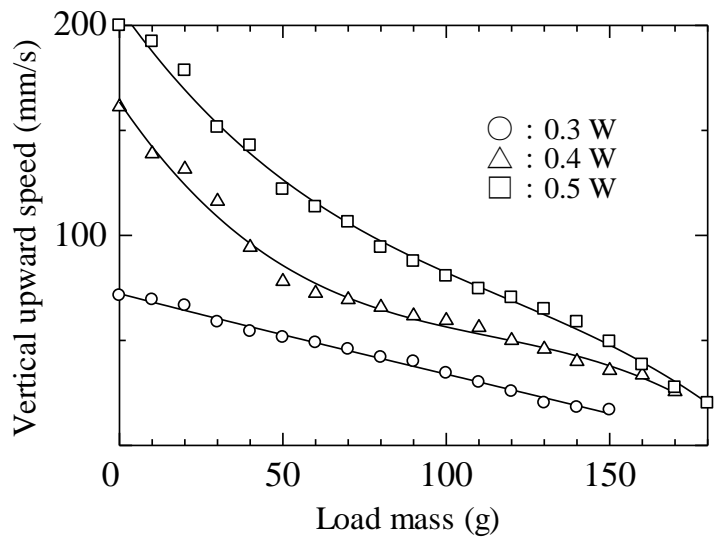

Figure 9. Relationship between load mass and vertical upward speed $(\mathrm{F}=3.7 \mathrm{~N})$.

When the attractive force is small, the movement characteristic demonstrates high speed and efficiency type characteristics. On the other hand, when the attractive force is large, it is a high propulsion type at low speed. Thus, by changing the attractive force of the holder unit, the propulsion characteristics change dramatically.

\section{Vibration Actuator System Capable of Movement over a Step}

As an application of this vibration actuator, a complex iron structure with a large-scale size was targeted. In particular, there is a step with a height of $25 \mathrm{~mm}$ at the cable joint in the main tower of the cable-stayed bridge. In order to realize movement over the step, a new vibration actuator system has been proposed. In order to move on an iron structure having a step, a flexible frame capable of deformation along the uneven part on the surface of the step and an attractive force for attracting the flexible frame to the structure are required. In the present paper, a silicone rubber material was used for the flexible frame, and the magnetic force generated by multiple permanent magnets was used as the attractive force.

Figure 10 shows an actuator system in which actuators A and B capable of reciprocating movement are connected by flexible silicone rubber material. The silicone rubber is 
divided into three parts. The length of silicone rubber $A$ is $L_{1}$, and that of silicone rubber $\mathrm{B}$ is $\mathrm{L}_{2}$. A magnetic wheel is attached to one end of each section of silicone rubber $\mathrm{A}$. By attaching a magnetic wheel to the tip of the actuator system, it is possible to expect an appropriate attractive force to the iron structure and the role of the guide in movement over a step. The magnetic wheel has a three-layer structure in which a ring-type permanent magnet is sandwiched between two acrylic disks having outer diameter $\mathrm{R}(\mathrm{mm})$ and a thickness of $2 \mathrm{~mm}$. In addition, auxiliary permanent magnets are placed at $\mathrm{x}(\mathrm{mm})$ and $-x(\mathrm{~mm})$ from origin $\mathrm{o}$ in order to attract the iron structures during movement of the step surface.
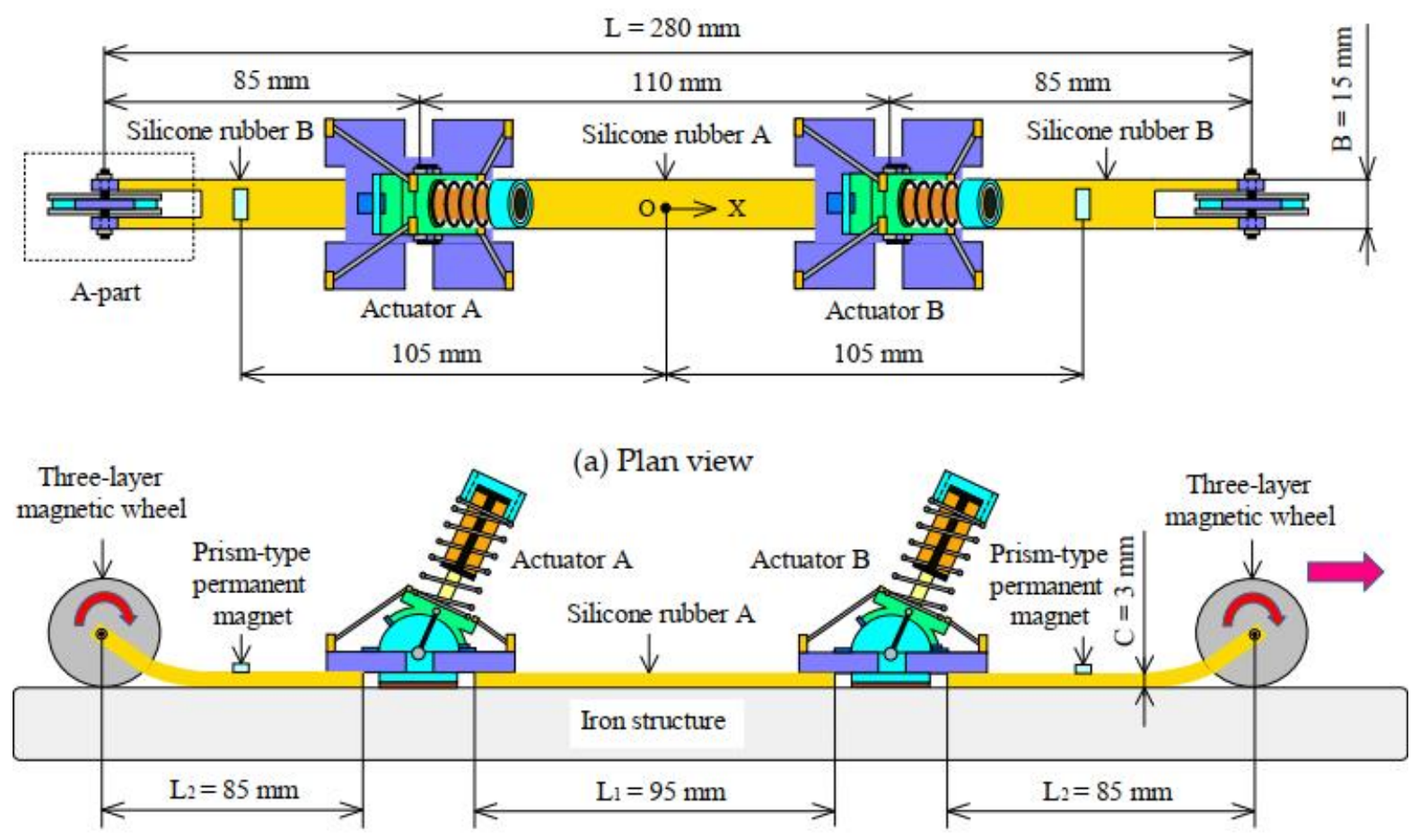

(b) Front view

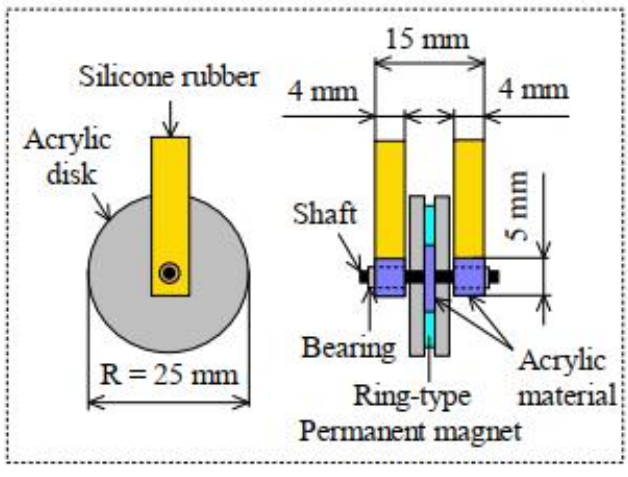

(c) Detail of Area A

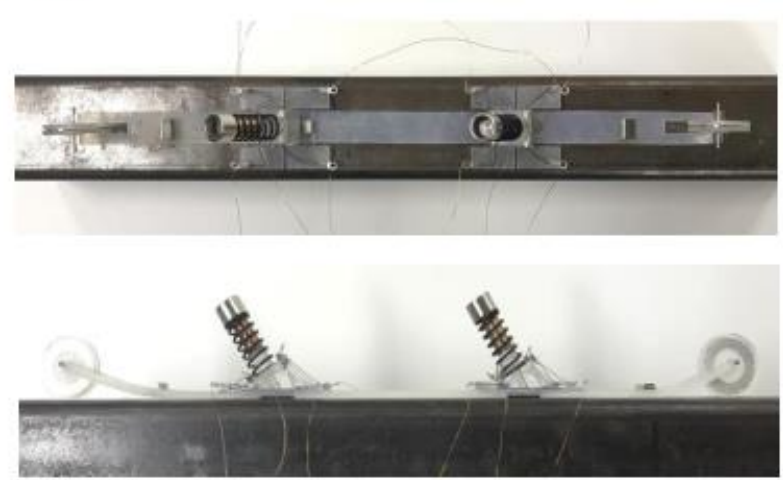

(d) Photograph of vibration actuator system.

Figure 10. Vibration actuator system capable of movement over a step. (a) Plan view. (b) Front view. (c) Detail of Area A. (d) Photograph of vibration actuator system.

The longitudinal stiffness of the silicone rubber material connecting two actuators has a significant effect on the traction characteristics and the movement characteristics of the step for the actuator system. Furthermore, the outer diameter and the attractive force of the magnetic wheel also affect the movement properties of the step. There are 
countless combinations in designing the actuator system, the following four indicators were introduced:

1. The total length of the actuator system is approximately $300 \mathrm{~mm}$ in consideration of portability.

2. In the future, a total of 20 wires will be required by installing a small-camera in the actuator system. In this paper, considering long cable traction over $50 \mathrm{~m}$, the traction force of the actuator system is more than $2 \mathrm{~N}$ (load mass: $200 \mathrm{~g}$ ).

3. Since a sensor will be mounted to the actuator in the future, the total mass of the actuator system should be less than $70 \mathrm{~g}$.

4. The height of the step that the actuator system moves does exceed $25 \mathrm{~mm}$ in the vertical plane.

Silicone rubber with a hardness of 30 with width $B=15 \mathrm{~mm}$ and lengths $L_{1}=95 \mathrm{~mm}$ and $\mathrm{L}_{2}=85 \mathrm{~mm}$, preliminary experiments with no wheels using silicone rubber of thickness $\mathrm{C}$ were performed. Table 2 shows the vertical upward speed when a load mass of $200 \mathrm{~g}$ is mounted to the actuator system and the thickness $C$ is varied. The input power to an electromagnet having one vibration component is set to $0.15 \mathrm{~W}$. Based on the obtained results, a $C$ value of $3 \mathrm{~mm}$ was selected for the silicone rubber material.

Table 2. Speed according to the thickness of silicone rubber.

\begin{tabular}{ccc}
\hline Thickness of Silicon Rubber C & Mounted Load Mass & Vertical Upward Speed \\
\hline $1 \mathrm{~mm}$ & $200 \mathrm{~g}$ & $5.8 \mathrm{~mm} / \mathrm{s}$ \\
\hline $2 \mathrm{~mm}$ & $200 \mathrm{~g}$ & $8.6 \mathrm{~mm} / \mathrm{s}$ \\
\hline $2.5 \mathrm{~mm}$ & $200 \mathrm{~g}$ & $13.0 \mathrm{~mm} / \mathrm{s}$ \\
\hline $3 \mathrm{~mm}$ & $200 \mathrm{~g}$ & $16.9 \mathrm{~mm} / \mathrm{s}$ \\
\hline $4 \mathrm{~mm}$ & $200 \mathrm{~g}$ & $3.3 \mathrm{~mm} / \mathrm{s}$ \\
\hline
\end{tabular}

The step movement characteristics of the three-layer magnetic wheel in the actuator system were then studied. An iron rail with a length of $200 \mathrm{~mm}$ and a step height of $12 \mathrm{~mm}$ was prepared. The dimensions of the silicone rubber were set to $\mathrm{B}=15 \mathrm{~mm}$, $\mathrm{L}_{1}=95 \mathrm{~mm}, \mathrm{~L}_{2}=85 \mathrm{~mm}$, and $\mathrm{C}=3 \mathrm{~mm}$. As the auxiliary attractive force, prism-type permanent magnets are arranged at $x=105 \mathrm{~mm}$ and $-105 \mathrm{~mm}$ in silicone rubber $B$. This $\mathrm{NdFeB}$ magnet has a length of $5 \mathrm{~mm}$, a width of $10 \mathrm{~mm}$, and a thickness of $2 \mathrm{~mm}$. The attractive force is $0.35 \mathrm{~N}$. The input power to the electromagnet of the vibration component was set as $0.15 \mathrm{~W}$. Table 3 shows the outer diameter $\mathrm{R}$ of the magnetic wheel and the vertical upward speed of the actuator system with no load mass when the attractive force of the magnetic wheel was set to $0.5 \mathrm{~N}$. The $\mathrm{NeFeB}$ ring permanent magnets were chosen to provide a constant attractive force. From this table, the outer diameter $\mathrm{R}$ of the magnetic wheels was selected to be $25 \mathrm{~mm}$.

Table 3. Speed according to the outer diameter of the magnetic wheel.

\begin{tabular}{cccc}
\hline $\begin{array}{c}\text { Outer Diameter of } \\
\text { Wheel R }\end{array}$ & $\begin{array}{c}\text { Dimension of Ring } \\
\text { Permanent Magnet }\end{array}$ & $\begin{array}{c}\text { Attractive Force of } \\
\text { Wheel }\end{array}$ & $\begin{array}{c}\text { Vertical Upward } \\
\text { Speed }\end{array}$ \\
\hline $20 \mathrm{~mm}$ & $\Phi 17.5 \times \Phi 7 \times 2 \mathrm{~mm}$ & $0.5 \mathrm{~N}$ & $16 \mathrm{~mm} / \mathrm{s}$ \\
\hline $25 \mathrm{~mm}$ & $\Phi 23 \times \Phi 13 \times 1 \mathrm{~mm}$ & $0.5 \mathrm{~N}$ & $18.4 \mathrm{~mm} / \mathrm{s}$ \\
\hline $30 \mathrm{~mm}$ & $\Phi 28 \times \Phi 17 \times 1 \mathrm{~mm}$ & $0.5 \mathrm{~N}$ & $15.3 \mathrm{~mm} / \mathrm{s}$ \\
\hline
\end{tabular}

The specifications of the silicone rubber and the magnetic wheel were determined by the above design, as shown in Figure 10. The overall length of the actuator system is $305 \mathrm{~mm}$, and the distance between the magnetic wheels is $\mathrm{L}=280 \mathrm{~mm}$. The width, height, and total mass of the actuator system are $38 \mathrm{~mm}, 42 \mathrm{~mm}$, and $68 \mathrm{~g}$, respectively. In this system, the attractive force $F$ of the holder unit was set to 3.7 N. Figure $10 \mathrm{~d}$ shows a photograph of vibration actuator system. 


\section{Locomotion Characteristics of the Proposed Actuator System}

The movement characteristics of the proposed vibration actuator system were measured using the experimental apparatus. Figure 11 shows the relationship between the load mass and the speed for vertical upward movement when powered by input powers of $0.3 \mathrm{~W}, 0.4 \mathrm{~W}$, and $0.5 \mathrm{~W}$ for the electromagnet having one vibration component. The figure indicates that the actuator system is able to climb upward at $24.0 \mathrm{~mm} / \mathrm{s}$ while pulling a load mass of $220 \mathrm{~g}$. Based on the measurement results and considering the above design indicators, a traction force of more than $2 \mathrm{~N}$ was realized.

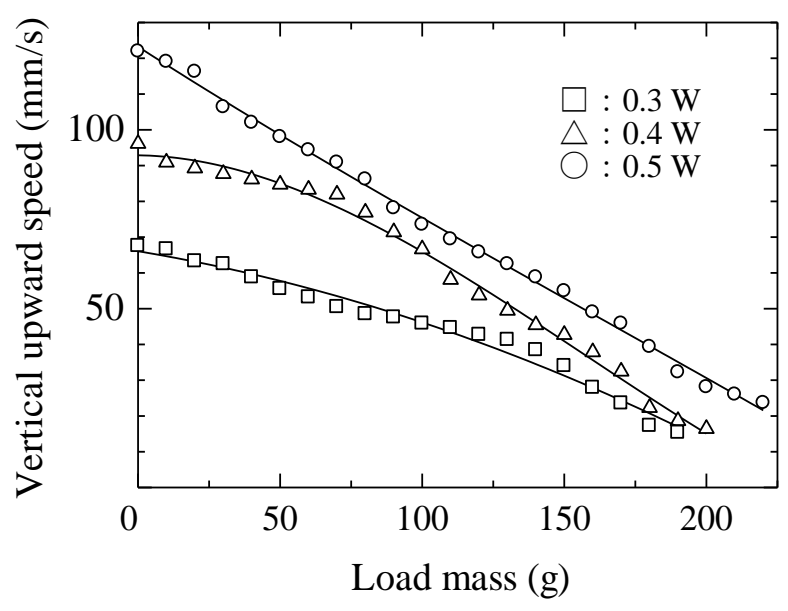

Figure 11. Relationship between load mass and vertical upward speed $(\mathrm{F}=3.7 \mathrm{~N})$.

Furthermore, the tilt angles $\beta_{1}$ and $\beta_{2}$ of the iron rail were varied as shown in Figure 12 . In this figure, $\beta_{1}$ indicates movement from a horizontal plane, and $\beta_{2}$ indicates movement from the slide-on-ceiling movement. Figure 13 shows the relationship between the tilt angle $\beta_{1}$ and angle $\beta_{2}$ of the iron rail from the horizontal plane, and the speed of the actuator system. In this figure, the solid line and dashed line indicate the variation in tilt angles $\beta_{1}$ and $\beta_{2}$, when powered the input power of $0.3 \mathrm{~W}$ for each vibration component. In this actuator system, both slide-on-ceiling and wall-climbing motions are possible.

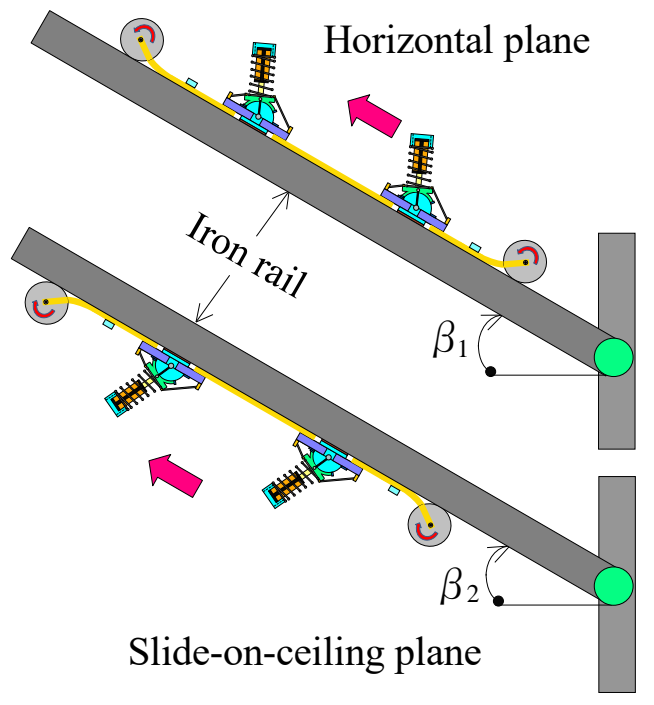

Figure 12. Vibration actuator system moving on the iron rail. 


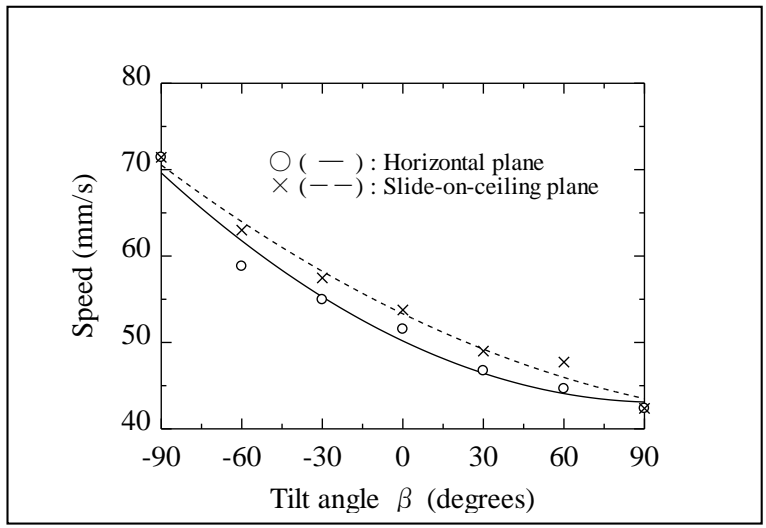

Figure 13. Relationship between the tilt angle $\beta$ of the iron rail and the movement speed.

In the experiment, the step pattern, as shown in Figure 14, was introduced. Iron rails with different step heights are prepared, and the average speed for the actuator system with no load mass was measured. In the measurement, the iron rail was tilted at angle $\alpha$ (degrees), and the distance from the front wheel to the rear wheel of the actuator system was set to $600 \mathrm{~mm}$. Figure 15 shows a schematic diagram of the movement on the step surface in the actuator system. As shown in Figure $15 b-d$, this system can move the step by the cooperative operation of the two actuators. No additional operation is required when the actuator system moves on the step surface.

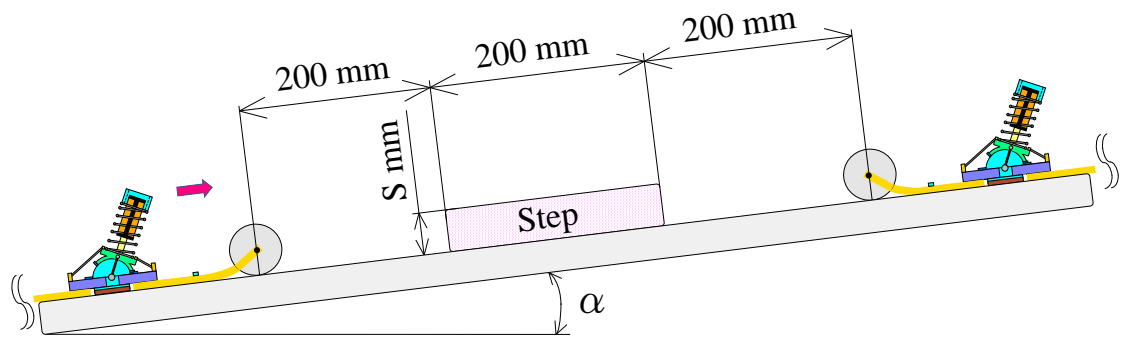

Figure 14. Step of an iron rail with tilt angle $\alpha$.

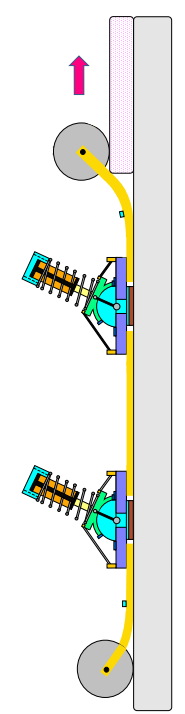

(a)

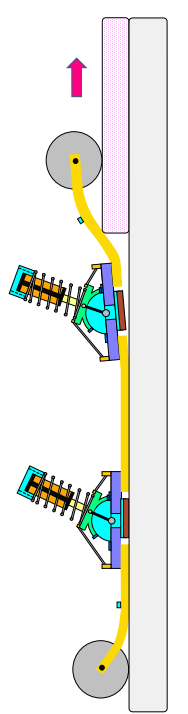

(b)

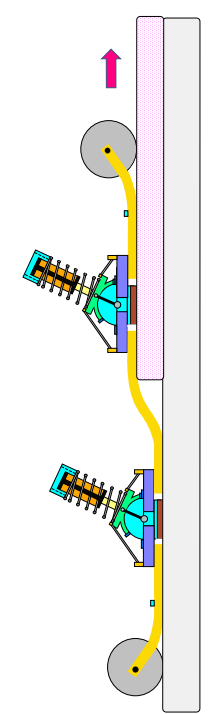

(c)

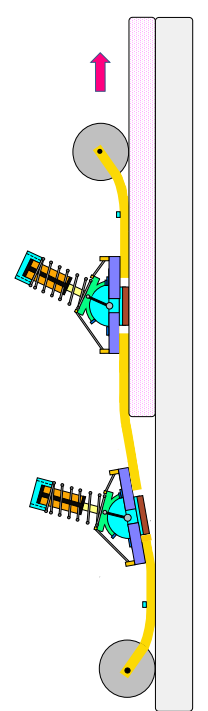

(d)

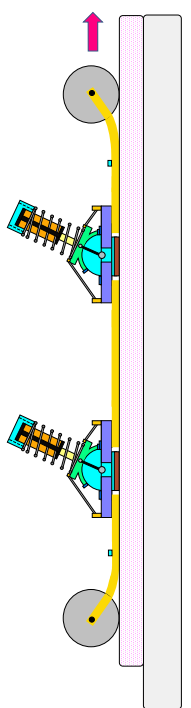

(e)

Figure 15. Movement on a stepped surface by the actuator system. (a) Start climbing the step, (b) Separation of iron rail and the actuator, (c) Coordinated operation of the actuator, (d) Separation of iron rail and the actuator, (e) End of step movement. 
Setting the tilt angle to $\alpha=0$ degrees, Table 4 shows the relationship between step height $S$ and the average speed of the actuator system by varying the input power to one vibration component as $0.1 \mathrm{~W}, 0.15 \mathrm{~W}$, and $0.2 \mathrm{~W}$. When the input power is $0.2 \mathrm{~W}$, it is possible to move over a step of height $S=48 \mathrm{~mm}$ at an average speed of $22 \mathrm{~mm} / \mathrm{s}$.

Table 4. Average speed according to step height.

\begin{tabular}{cccc}
\hline Height h of Sep S & $\begin{array}{c}\text { Speed of Input } \\
\text { Power 0.1 W }\end{array}$ & $\begin{array}{c}\text { Speed of Input } \\
\text { Power 0.15 W }\end{array}$ & $\begin{array}{c}\text { Speed of Input } \\
\text { Power 0.2 W }\end{array}$ \\
\hline $0 \mathrm{~mm}$ & $21.3 \mathrm{~mm} / \mathrm{s}$ & $26.0 \mathrm{~mm} / \mathrm{s}$ & $48.3 \mathrm{~mm} / \mathrm{s}$ \\
$6 \mathrm{~mm}$ & $18.6 \mathrm{~mm} / \mathrm{s}$ & $23.2 \mathrm{~mm} / \mathrm{s}$ & $36.3 \mathrm{~mm} / \mathrm{s}$ \\
$12 \mathrm{~mm}$ & $16.7 \mathrm{~mm} / \mathrm{s}$ & $21.9 \mathrm{~mm} / \mathrm{s}$ & $32.9 \mathrm{~mm} / \mathrm{s}$ \\
$18 \mathrm{~mm}$ & $15.7 \mathrm{~mm} / \mathrm{s}$ & $20.6 \mathrm{~mm} / \mathrm{s}$ & $31.8 \mathrm{~mm} / \mathrm{s}$ \\
$24 \mathrm{~mm}$ & $15.2 \mathrm{~mm} / \mathrm{s}$ & $20.0 \mathrm{~mm} / \mathrm{s}$ & $28.5 \mathrm{~mm} / \mathrm{s}$ \\
$30 \mathrm{~mm}$ & $14.6 \mathrm{~mm} / \mathrm{s}$ & $18.4 \mathrm{~mm} / \mathrm{s}$ & $25.5 \mathrm{~mm} / \mathrm{s}$ \\
$36 \mathrm{~mm}$ & $14.4 \mathrm{~mm} / \mathrm{s}$ & $16.7 \mathrm{~mm} / \mathrm{s}$ & $24.9 \mathrm{~mm} / \mathrm{s}$ \\
$42 \mathrm{~mm}$ & - & $14.9 \mathrm{~mm} / \mathrm{s}$ & $22.4 \mathrm{~mm} / \mathrm{s}$ \\
$48 \mathrm{~mm}$ & - & - & $22.0 \mathrm{~mm} / \mathrm{s}$ \\
\hline
\end{tabular}

Table 5 shows the relationship between the tilt angle of the iron rail and the average speed in the actuator system when the input power to one vibration component was set to $0.2 \mathrm{~W}$. In the table, -90 degrees indicates the vertically downward direction, and 90 degrees indicates the vertically upward direction. In addition, 0 degrees indicates the horizontal direction. This actuator system can move at an average speed of $18.1 \mathrm{~mm} / \mathrm{s}$ without control on an iron rail having a step of $S=25 \mathrm{~mm}$ in the vertically upward direction, which is difficult for various robots. By installing multiple small-cameras on the actuator system, it is possible to inspect the appearance of complex iron structures. Thus, the experimental results show the possibility of application to visual inspection of large bridges such as cable-stayed bridges. Finally, the actuator system was prototyped with the bridge girder structure as the inspection target. A movement test of the actuator system in a frame consisting of vertical and horizontal surfaces, as shown in Figure 16, was performed. As shown in the figure, the measurement was performed by dividing the frame into three regions. As shown in Figure 17, three ring-type permanent magnets were newly arranged into silicone rubber A. The ring-type permanent magnet is an NdFeB magnet with an outer diameter of $11 \mathrm{~mm}$, an inner diameter of $6 \mathrm{~mm}$, and a thickness of $8 \mathrm{~mm}$. The attractive force is $0.95 \mathrm{~N}$. An acrylic rod with outer diameter of $5.9 \mathrm{~mm}$ having a shaft with diameter of $1 \mathrm{~mm}$ was inserted into each ring-type magnet. These were attached to an acrylic base with two bearings. The magnets are arranged at $x=0 \mathrm{~mm}, x=20 \mathrm{~mm}$ and $x=-20 \mathrm{~mm}$ in silicone rubber A. The average speed in each region is shown in Table 6. From the table, this actuator system can move in the iron frame at an average speed of $12.1 \mathrm{~mm} / \mathrm{s}$. In particular, when movement within the frame, the movement speed of the actuator system in Range 1 has been significantly reduced as shown in Table 6. As the actuator system moves around the corners of the frame, one actuator must overcome the attractive force between the permanent magnets attached to the silicone rubber $\mathrm{A}$ and the frame. In addition to this, the influence of the system's own weight has a considerable effect, and the movement speed in Range 1 is lower than in other ranges. Due to the insufficient traction force of the vibration actuator, such a decrease in movement speed of the actuator system occurred. Although, this actuator system can move from a vertical surface to a ceiling surface, which is difficult even for a robot equipped with a complicated control system. Under any circumstances, no additional operation is required when the actuator system moves in the iron frame. 
Table 5. Average speed according to the tilt angle of an iron rail.

\begin{tabular}{|c|c|c|c|c|}
\hline $\begin{array}{l}\text { Tilt Angle } \alpha \text { of } \\
\text { Iron Rail }\end{array}$ & $\begin{array}{l}\text { Speed of Step S } \\
\quad=0 \mathrm{~mm}\end{array}$ & $\begin{array}{l}\text { Speed of Step S } \\
\quad=15 \mathrm{~mm}\end{array}$ & $\begin{array}{l}\text { Speed of Step S } \\
=20 \mathrm{~mm}\end{array}$ & $\begin{array}{l}\text { Speed of Step S } \\
=25 \mathrm{~mm}\end{array}$ \\
\hline-90 & $71.4 \mathrm{~mm} / \mathrm{s}$ & $49.9 \mathrm{~mm} / \mathrm{s}$ & $47.6 \mathrm{~mm} / \mathrm{s}$ & $38.6 \mathrm{~mm} / \mathrm{s}$ \\
\hline-60 & $58.8 \mathrm{~mm} / \mathrm{s}$ & $46.2 \mathrm{~mm} / \mathrm{s}$ & $42.3 \mathrm{~mm} / \mathrm{s}$ & $34.6 \mathrm{~mm} / \mathrm{s}$ \\
\hline-30 & $52.9 \mathrm{~mm} / \mathrm{s}$ & $38.5 \mathrm{~mm} / \mathrm{s}$ & $37.3 \mathrm{~mm} / \mathrm{s}$ & $29.5 \mathrm{~mm} / \mathrm{s}$ \\
\hline 0 & $48.3 \mathrm{~mm} / \mathrm{s}$ & $32.3 \mathrm{~mm} / \mathrm{s}$ & $31.0 \mathrm{~mm} / \mathrm{s}$ & $24.9 \mathrm{~mm} / \mathrm{s}$ \\
\hline 30 & $46.7 \mathrm{~mm} / \mathrm{s}$ & $31.5 \mathrm{~mm} / \mathrm{s}$ & $28.3 \mathrm{~mm} / \mathrm{s}$ & $22.5 \mathrm{~mm} / \mathrm{s}$ \\
\hline 60 & $44.6 \mathrm{~mm} / \mathrm{s}$ & $25.9 \mathrm{~mm} / \mathrm{s}$ & $22.5 \mathrm{~mm} / \mathrm{s}$ & $20.2 \mathrm{~mm} / \mathrm{s}$ \\
\hline 90 & $42.4 \mathrm{~mm} / \mathrm{s}$ & $23.7 \mathrm{~mm} / \mathrm{s}$ & $21.5 \mathrm{~mm} / \mathrm{s}$ & $18.1 \mathrm{~mm} / \mathrm{s}$ \\
\hline
\end{tabular}

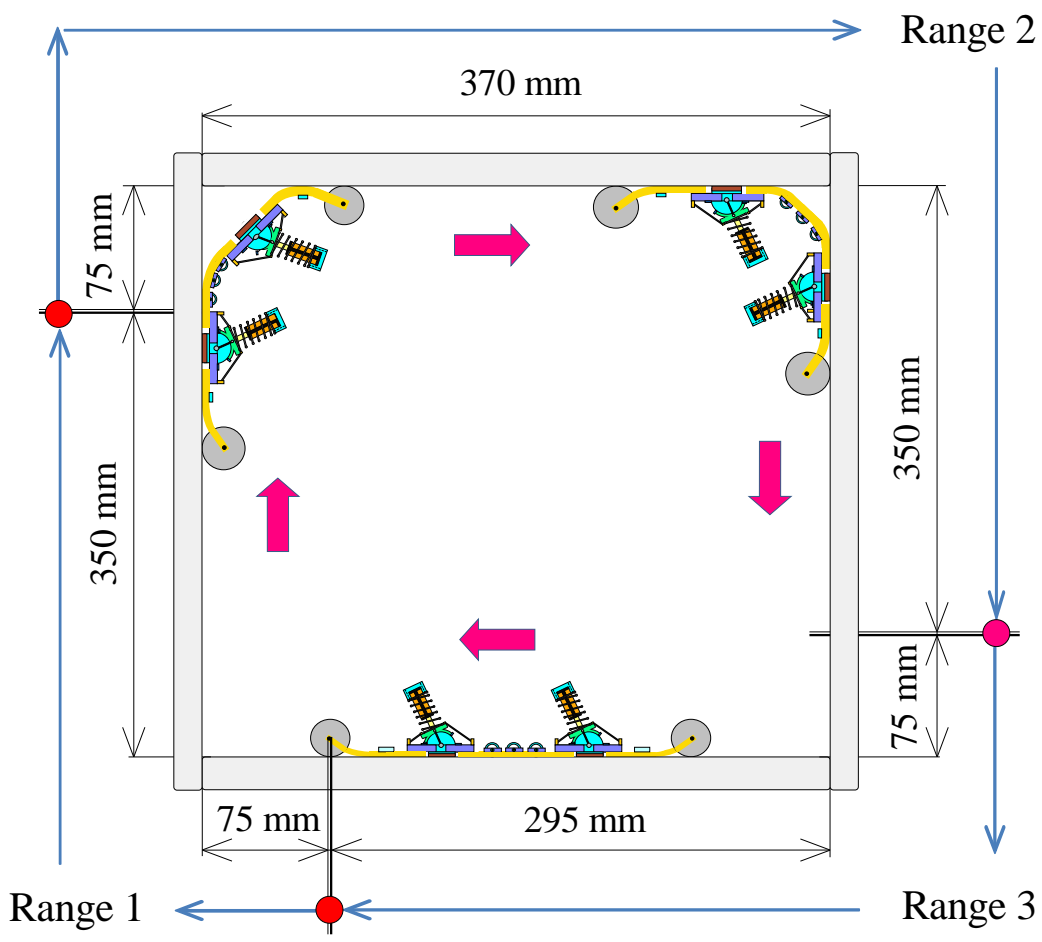

Figure 16. Movement range in a frame.

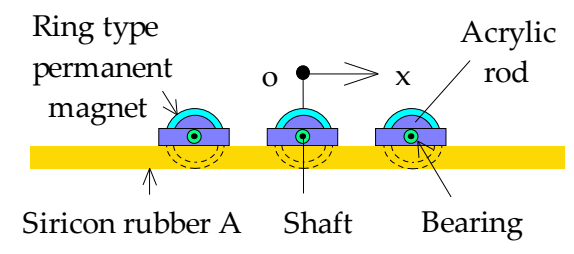

(a) Front view

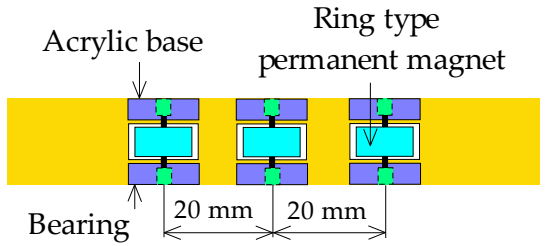

(b) Plan view

Figure 17. Newly arranged ring-type permanent magnet. (a) Front view of placed magnets, (b) Plan view of placed magnets.

Table 6. Average speed of the actuator system in a frame.

\begin{tabular}{cccc}
\hline Range & Distance of Movement & Transit Time & Average Speed \\
\hline 1 & $425 \mathrm{~mm}$ & $16.8 \mathrm{~s}$ & $25.3 \mathrm{~mm} / \mathrm{s}$ \\
2 & $795 \mathrm{~mm}$ & $107.4 \mathrm{~s}$ & $7.4 \mathrm{~mm} / \mathrm{s}$ \\
3 & $370 \mathrm{~mm}$ & $7.7 \mathrm{~s}$ & $48.1 \mathrm{~mm} / \mathrm{s}$ \\
\hline Total $(1+2+3)$ & $1590 \mathrm{~mm}$ & $131.9 \mathrm{~s}$ & $12.1 \mathrm{~mm} / \mathrm{s}$ \\
\hline
\end{tabular}




\section{Conclusions}

Robots require many control devices. In addition, it is generally difficult for a robot to travel on a step on a vertical surface due to its own weight. Therefore, steps and movements within the frame by driving a simple device have not yet been realized by various robots and other devices. Targeting these problems, a new type of an actuator system has been developed for the movement of steps that does not depend on the angle of the moving surface. When the input power is set and the power is input to an electromagnet, utilizing the coordinated operation of two vibration components, the actuator system that can automatically move on steps and in the frame has been realized.

First, by expanding the operating principle proposed by the authors, a new type of a vibration actuator capable of reciprocating with a scale size of less than $50 \mathrm{~mm}$ in all dimensions was prototyped and tested. When the attractive force of a holder unit decreases, the experimental results reveal that the maximum efficiency of the vibration actuator capable of reciprocating movement was $28.1 \%$ for the case of the weight of the actuator when the input power into the electromagnet was $0.1 \mathrm{~W}$. An actual machine test showed high movement efficiency as a small-scale linear actuator. On the other hand, when the attractive force of the holder unit increases, maximum pulling power was $1.8 \mathrm{~N}$.

The vibration actuator system, in which two vibration actuators and a wheel having a magnetic force were connected by a silicone rubber material, was prototyped. An iron structure having a step was prepared, and the movement characteristics of the vibration actuator system were measured. In the horizontal plane, the system can move over a step of $48 \mathrm{~mm}$, and in the vertical plane, the system can move over a step of $25 \mathrm{~mm}$. Within the step height shown above, it has been demonstrate that this actuator system can be driven with only a simple device. Once the input current to the vibration component is set, the actuator system can move on a vertical surface with a step without any operation and control.

Further, this paper demonstrates the possibility of visual inspection of large complex iron structures. In addition, the experimental results show that the average speed of the actuator system in a frame consisting of horizontal and vertical surfaces was $12.1 \mathrm{~mm} / \mathrm{s}$. In such in-frame movement, when the input current to the actuator system is set, the system can automatically movement in the frame.

In the future, we plan to design an actuator that can move in all directions over 360 degrees and develop a system equipped with an automatic tapping device and multiple micro cameras. For this purpose, the traction characteristics of the vibration actuator must be improved by changing the magnetic circuit in the propulsion unit.

Author Contributions: Conceptualization, H.Y.; Data curation, H.Y. and Y.I.; Funding acquisition, H.Y.; Investigation, H.Y.; Project administration, H.Y.; Supervision, H.Y.; Writing—original draft, H.Y.; Writing-review \& editing, H.Y. All authors have read and agreed to the published version of the manuscript.

Funding: This work was supported by JSPS KAKENHI Grant Number JP18K041.

Institutional Review Board Statement: Not applicable.

Informed Consent Statement: Not applicable.

Data Availability Statement: Not applicable.

Conflicts of Interest: The authors declare no conflict of interest.

\section{References}

1. Fukuda, T.; Matsuura, H.; Arai, F.; Nishibori, K.; Sakauchi, H.; Yoshi, N. A Study on Wall Surface Mobile Robots. Trans. Japan Soc. Mec. Eng. 1992, 58, 286-293.

2. Kanada, A.; Giardina, F.; Howison, T.; Mashimo, T.; Iida, F. Reachability Improvement of a Climbing Robot based on Large Deformations induced by Tri-Tube Soft Actuators. Soft Robot. 2019, 6, 4. [CrossRef] [PubMed]

3. Wang, W.; Wang, K.; Zhang, H.; Zhang, J. Internal Force Compensating Method for Wall-Climbing Caterpillar Robot. In Proceedings of the IEEE International Conference on Robotics and Automation, Anchorage, AK, USA, 3-7 May 2010; pp. $2816-2820$. 
4. Kute, C.; Murphy, M.; Menguc, Y.; Sitti, M. Adhesion Recovery and Passive Peeling in a Wall Climbing Robot using Adhesives. In Proceedings of the IEEE International Conference on Robotics and Automation, Anchorage, AK, USA, 3-7 May 2010; pp. $2797-2802$.

5. Xu, F.; Wang, X.; Jiang, G. Design and Analysis of a Wall-Climbing Robot Based on a Mechanism Utilizing Hook-Like Claws. Int. J. Adv. Robot. Syst. 2012, 9, 1-12. [CrossRef]

6. Funatsu, M.; Kawasaki, Y.; Kawasaki, S.; Kikuchi, K. Development of cm-scale Wall Climbing Hexapod Robot with Claws. In Proceedings of the International Conference on Design Engineering and Science, Pilsen, Czech, 31 August-3 September 2014; pp. 101-106.

7. Kim, S.; Spenko, M.; Trujillo, S.; Heyneman, B.; Mattoli, V.; Cutkosky, M.R. Whole body adhesion hierarchical directional and distributed control of adhesive forces for a climbing robot. In Proceedings of the IEEE International Conference on Robotics and Automation, Rome, Italy, 10-14 April 2007.

8. Subramanyam, A.; Mallikarjuna, Y.; Suneel, S.; Kumar, L.B. Design and Development of a Climbing Robot for Several Applications. Int. J. Adv. Comput. Technol. 2011, 3, 15-23.

9. Jae-Uk, S.; Donghoon, K.; Ong-Heon, J.; Hyun, M. Micro aerial vehicle type wall-climbing robot mechanism. In Proceedings of the IEEE RO-MAN International Symposium on Robot and Human Interactive Communication, Gyeongju, Korea, 26-29 August 2013; pp. $722-725$.

10. Mahamud, N.; Shahriar, G.M.; Khan, H.U.; Sharmin, S.; Lisa, N.J. ALW drone: A new design and efficient approach. In Proceedings of the IEEE 19th International Conference on Computer and Information Technology (ICCIT), Dhaka, Bangladesh, 18-20 December 2017; pp. 474-479. [CrossRef]

11. Morita, M.; Kinjo, H.; Sato, S.; Sulyyon, T.; Anezaki, T. Autonomous flight drone for infrastructure (transmission line) inspection. In Proceedings of the IEEE International Conference on Intelligent Informatics and Biomedical Sciences (ICIIBMS), Okinawa, Japan, 24-26 November 2017; pp. 198-201. [CrossRef]

12. Lee, G.; Park, J.; Kim, H.; Seo, T.W. Wall Climbing Robots with Track-wheel Mechanism. In Proceedings of the IEEE International Conference on Machine Learning and Computing, Singapore, 26-28 February 2011; pp. 334-337.

13. Khirade, N.; Sanghi, R.; Tidke, D. Magnetic Wall Climbing Devices-A Review. In Proceedings of the International Conference on Advances in Engineering \& Technology, Singapore, 29-30 March 2014; pp. 55-59.

14. Kim, J.H.; Park, S.M.; Kim, J.H.; Lee, J.Y. Design and Experimental Implementation of Easily Detachable Permanent Magnet Reluctance Wheel for Wall-Climbing Mobile Robot. J. Magn. 2010, 15, 128-131. [CrossRef]

15. Yaguchi, H.; Izumikawa, T. Wireless In-Piping Actuator Capable of High-Speed Locomotion by a New Motion Principle. IEEE/ASME Trans. Mechatron. 2013, 18, 1367-1376. [CrossRef]

16. Yaguchi, H.; Sakuma, S. Vibration Actuator Capable of Movement on Magnetic Substance Based on New Motion Principle. J. Vibroeng. 2017, 19, 1494-1508.

17. Yaguchi, H.; Sakuma, S. Improvement of a Magnetic Actuator Capable of Movement on a Magnetic Substance. IEEE Trans. Magn. 2016, 52, 1-4. [CrossRef]

18. Yaguchi, H.; Kimura, I.; Sakuma, S. A Novel Actuator System Combining Mechanical Vibration and Magnetic Wheels Capable of Rotational Motion Using Shape Memory Alloy Coils. Actuator 2019, 8, 4. [CrossRef]

19. Yaguchi, H.; Kimura, I.; Sakuma, S. A new type of rotary magnetic actuator system using electromagnetic vibration and wheel. Actuator 2020, 9, 51. [CrossRef] 